\title{
MODEL KEPUASAN AWAK KAPAL (STUDI KASUS PADA PT. FOC INDONESIA)
}

\author{
* D.Heriyanto ${ }^{1}$ \\ ${ }^{1}$ Sekolah Tinggi Penerbangan Aviasi, Jakarta, Indonesia
}

*Email Korespondensi:

heriyanto.se.mm.tr@gmail.com

\section{ARTIKEL INFORMASI}

Diterima:

24 Juni 2021

Direvisi:

12 Juli 2021

Dipublikasi:

22 Juli 2021

\begin{abstract}
ABSTRAK
Penelitian ini bertujuan untuk menganalisis variabel Kualitas Pelayanan berhubungan signifikan dengan Kepuasan bagi awak kapal pada PT. FOC Indonesia, untuk menganalisis Kompensasi berhubungan signifikan dengan Kepuasan bagi awak kapal pada PT. FOC Indonesia, dan untuk menganalisis variabel Kualitas Pelayanan dan Kompensasi secara bersama-sama berhubungan signifikan dengan Kepuasan bagi awak kapal pada PT. FOC Indonesia. Penelitian ini dilakukan di PT. FOC Indonesia Jakarta, dengan mengadakan metode Kuantitatif yang dikenal dengan metode explanatory research. Adapun populasi penelitiannya adalah 146 orang anak buah kapal PT. FOC Indonesia Jakarta. Jumlah sampel penelitian diambil simple random sampling sebanyak 60 orang. Data dihimpun melalui instrument dalam bentuk kuesioner dengan model likert scale dengan menggunakan skala lima yang telah diuji validitas dan reliabilitasnya. Implikasi dari hasil penelitian adalah Kepuasan Awak Kapal PT. FOC Indonesia Jakarta dapat diwujudkan dengan memberikan kualitas pelayanan kepada awak kapal dan memberikan kompensasi yang baik kepada para awak kapal sehingga perusahaan pengawakan dapat memenangkan persaingan pada pasar perekrutan awak kapal.
\end{abstract}

Kata Kunci: Kualitas Pelayanan, Kompensasi, Kepuasan

\section{PENDAHULUAN}

NKRI (Negara Kesatuan Republik Indonesia) sebagai negara kepulauan terbesar 12 di dunia sangat tepat jika memiliki predikat sebagai negara maritime yang memiliki potensi yang sangat besar dalam dunia kemaritiman sehingga sudah selayaknya jika Indonesia mempersiapkan diri agar dapat berkontribusi didalamnya dengan mempersiapkan Sumber Daya Manusia (SDM) laut dengan mendirikan sekolah - sekolah pelayaran diberbagai wilayah Indonesia, Hal ini pula yang telah menjadi dasar pemikiran steak holder untuk mendirikan suatu perusahaan pelayaran yang bergerak di bidang pelayanan jasa pengawakan kapal laut sebagai salah satu wadah penyaluran kerja bagi para SDM laut atau awak kapal sebagai pengguna jasanya. 
Namun karena pada kenyataannya saat ini masih banyak kekecewaan yang dirasakan oleh para pengguna jasa pengawakan (awak kapal) di perusahaan-perusahaan pengawakan maka dalam tugas penulisan Tesis ini peneliti mencoba untuk mencari solusi dengan membuat penelitian pada salah satu perusahaan jasa pengawakan kapal niaga Internasional yaitu PT. FOC Indonesia tersebut. Sekelumit tentang keberadaan perusahaan PT. FOC Indonesia yang kami jadikan tempat penelitian bahwa PT. FOC Indonesia didirikan tidak semata mata berorientasi terhadap perolehan profit semata namun jika memungkinkan bisa bermanfaat lebih luas lagi, antara lain bisa memberikan kontribusi terhadap pemerintah dalam membantu menyalurkan para awak kapal niaga baik itu dari lulusan sekolah tinggi pelayaran, akademi pelayaran maupun lembaga pendidikan dan latihan pelayaran yang lain yang dibawah naungan pemerintah (Kementerian Perhubungan) maupun lulusan dari lembaga pendidikan pelayaran yang dikelola oleh pihak swasta.

Sumber dari Direktorat Perhubungan Laut, Indonesia meluluskan tenaga kerja awak kapal niaga baru sebanyak 34,073 orang dalam setiap tahunnya Dengan demikian tata pengelolaan atau manajemen dari perusahaan pengawakan yang berkontribusi sebagai tempat penyaluran bagi mereka untuk mendapatkan pekerjaan itu perlu mendapat perhatian besar. Dengan kualitas pelayanan yang ditujukan untuk memuaskan pengguna jasanya yang dimaksud yaitu para awak kapal niaga atau tenaga kerja pelaut sehingga mereka bisa tetap senang dan semangat dalam menjalankan profesinya dan lebih dari itu bisa mengupayakan agar profesi sebagai pelaut tersebut akhirnya bisa semakin digemari oleh para generasi muda di Indonesia.

Hal tersebut diatas hanya akan bisa diwujudkan dengan mengupayakan kepuasan menjalani profesi pada diri para awak kapal niaga atau Pelaut yang sudah ada terlebih dahulu. Sehingga di dalam penelitian ini yang menjadi tema sentral penelitian adalah kepuasan dalam hal pelayanan bagi para awak kapal niaga pada PT. FOC Indonesia. Argumentasi yang mendasari pilihan atas tema ini adalah, Pertama, Masih banyak perusahaan atau organisasi yang mengabaikan perhatian untuk memberikan pelayanan yang terbaik atau kualitas pelayanan terhadap pelanggan atau dengan kata lain pelayanan terbaik masih sebatas slogan saja. padahal hal itu yang kelak akan menjadi indikator bagi klien untuk bersedia menjalin hubungan kerjasama yang berkesinambungan (long term cooperation). Assael menyebutkan bahwa "A satisfied customer is your best sales person. Satisfied customer influence friends and relative to buy, dissatisfied customers inhibit sales" (Seorang pelanggan yang puas merupakan penjual perorangan terbaik. Pelanggan yang puas akan mempengaruhi rekan-rekannya dan kecenderungan membeli, pelanggan yang tidak puas akan menghambat penjualan). Kepuasan adalah hal yang sangat didamba bagi semua orang pada saat ini , sehingga siapapun yang mendirikan usaha baik barang maupun jasa agar memperhatikan dengan seksama terhadap masalah kepuasan ini.

Kedua, Harus segera di temukan suatu metode agar kepuasan para pengguna jasa perusahaan pengawakan seperti ini dapat di wujudkan dengan optimal dengan melakukan analisa terhadap faktor faktor yang mempengaruhi terhadap kepuasan tersebut antara lain dengan menyorot masalah kualitas pelayanan danpemberian kompensasi. Ketiga, peneliti ingin memberikan gambaran atau inspirasi kepada pelaku bisnis yang lain khususnya yang bergerak pada bidang jasa pengawakan kapal niaga dan bidang usaha yang lain pada umumnya agar bisa memberikan inspirasi bahwa masalah kepuasan bagi pengguna jasa atau produk agar bisa menjadi bagian dari misi dari suatu perusahaan itu didirikan.

Berdasarkan latar belakang penelitian yang telah diuraikan, maka dapat diidentifikasi beberapa masalah yang ditemui dalam menganalisis hubungan kualitas pelayanan dan kompensasi terhadap kepuasan awak kapal niagapada PT. FOC Indonesia seperti ;

1) Masih banyak adanya kekecewaan yang dirasakan oleh para pelaut atau awak kapal sebagai pengguna jasa dari perusahaan pengawakan terkait cara pelayanan para staf di perusahaan pengawakan yang ada. Awak kapal merasa tidak dilayani secara sepenuhnya,

2) Awak kapal tidak mendapatkan informasi yang jelas tentang penempatannya dikapal terkait dengan jadwal keberangkatan, rute kapal dimana dia akan ditempatkan, type kapal dengan ship's particularnya sehingga awak kapal mengalami situasi yang dirasa tidak pasti,

3) Awak kapal tidak mendapat dukungan dari perusahaan terkait dengan biaya-biaya formalitas proses keberangkatan seperti perpanjangan dokumen-dokumen pelaut termasuk juga medical check up dan lainnya,

4) Awak kapal tidak mendapatkan informasi yang tansparan tentang besarnya kompensasi (Gaji) dan system penggajiannya, 
5) Awak kapal merasa tidak puas dengan jumlah Kompensasi (gaji ) yang diterima maupun tunjangan kerja lainnya dan cara kordinasi dengan perusahaan.

Rumusan permasalahan yang ada di atas di rumuskan sebagai berikut;

1) Apakah variabel Kualitas Pelayanan berhubungan signifikan terhadap Kepuasan bagi awak kapal pada PT. FOC Indonesia?

2) Apakah variabel Kompensasi berhubungan signifikan terhadap Kepuasan bagi awak kapal pada PT. FOC Indonesia?

3) Apakah variabel Kualitas Pelayanan dan Kompensasi secara bersama-sama berhubungan signifikan terhadap Kepuasan bagi awak kapal pada PT. FOC Indonesia?

\section{KAJIAN PUSTAKA}

Kualitas pelayanan (service quality) atau sering juga disebut mutu pelayanan, menurut Parasuraman dalam Soetjipto (2007:18) adalah "seberapa jauh perbedaan antara kenyataan dan harapan para pelanggan atas pelayanan yang mereka terima atau peroleh.Harapan merupakan keinginan para pelanggan dari pelayanan yang mungkin diberikan oleh perusahaan". Fitzsimmons dalam Soetjipto (2007:18) mengemukakan bahwa : "Kualitas pelayanan dapat diketahui dengan cara membandingkan persepsi para pelanggan atas pelayanan yang nyata-nyata mereka terima atau peroleh dengan dengan pelayanan yang sesungguhnya mereka harapkan dan inginkan. Jika kenyataan lebih besar dari yang diharapkan, maka pelayanan dapat dikatakan bermutu, sedangkan jika kenyataan kurang dari yang diharapkan, maka pelayanan dapat dikatakan tidak bermutu apabila kenyataan sama dengan harapan, maka pelayanan disebut memuaskan" Sebagaimana dikemukakan oleh Ziethaml dan Bitner (2007:7), perusahaan yang bergerak di bidang jasa sangat tergantung pada kualitas pelayanan yang diberikan. Kualitas pelayanan dalam pengertian dibedakan dahulu pada : "pelayanan merupakan satu bentuk kesatuan kerja daripada peralatan dan perlengkapan atau apa saja dan karyawan untuk penyediaan akomodasi dan kegiatan yang diinginkan oleh orang atau publik atau pelaksanaan setiap tugas atau pekerjaan untuk orang lain" Menurut Moekijat (2006:24) yang dimaksud pelayanan adalah, "Suatu kegiatan atau aktivitas yang sifatnya berwujud atau tidak berwujud yang dilakukan untuk melayani konsumen dengan memberikan barang atau jasa yang disertai atau tanpa pemindahan kepemilikan atas barang atau jasa".

Sebenarnya tidaklah mudah mendefinisikan kualitas dengan tepat, menurut Assauri (2007:321) pengertian kualitas adalah, "faktor-faktor yang tepat dalam suatu barang atau jasa yang menyebabkan barang atau jasa tersebut sesuai dengan tujuan untuk apa barang atau jasa itu ditujukan dan dimaksudkan." Berdasar unsur-unsur diatas Tjiptono (2007:42) mendefinisikan kualitas yang cakupannya lebih luas, yaitu kualitas merupakan suatu kondisi dinamis yang berhubungan dengan produk, jasa, manusia, proses dan lingkungan yang memenuhi atau melebihi harapan.

Dengan demikian definisi kualitas pelayanan adalah bahwa kualitas harus dihubungkan dengan harapanharapan konsumen dan memuaskan kebutuhan serta permintaan mereka, namun tidak berarti harus selalu menuruti atau tunduk terhadap keinginan konsumen. Disinilah pentingnya kemampuan professional para pemberi jasa. Salah satu cara utama dalam membedakan sebuah perusahaan jasa adalah mengetengahkan dengan konsisten jasa yang berkualitas lebih tinggi daripada pesaing mereka. Kuncinya adalah menyesuaikan atau melebihi harapan kualitas para pelanggan.Harapan mereka merupakan hasil dari pengalaman mereka, kata-kata orang, dan iklan perusahaan jasa. Pelanggan memilih para penyedia jasa atas dasar ini dan setelah menerima jasa, mereka akan membandingkan pelayanan yang dirasakan dengan dengan pelayanan yang dikehendaki. Jika pelayanan yang dirasakan berada di bawah pelayanan yang diharapkan, pelanggan akan kehilangan kepercayaan kepada penyedia jasa tersebut, sedangkan apabila pelayanan yang dirasakan sesuai dengan kualitas yang dikehendaki, mereka akan menggunakan lagi penyedia jasa tersebut.

Goetsch dan Davis (2007:32) mendefinisikan kualitas yang cakupannya lebih luas, yaitu kualitas merupakan suatu kondisi dinamis yang berhubungan dengan produk, jasa, manusia, proses dan lingkungan yang memenuhi atau melebihi harapan. Menurut Flippo (2005:119) pengertian kompensasi adalah : "Wages is defined as the adequate and equitable renumeration of personnel for their constribution to organizational objectives". Selanjutnya menurut Handoko (2007:155): "Kompensasi adalah segala sesuatu yang diterima para karyawan sebagai balas jasa untuk kerja mereka". Menurut Hasibuan (2005:118) sebagai berikut : “ Kompensasi adalah semua pendapatan yang berbentuk uang atau barang langsung atau tidak langsung yang diterima karyawan sebagai imbalan atau jasa yang diberikan kepada perusahaan". 
Jadi dapat dijelaskan bahwa kompensasi merupakan balas jasa yang diberikan oleh perusahaan kepada tenaga kerja yang dapat dinilai dengan uang dan merupakan kecenderungan diberikan secara tetap.Bagi tenaga kerja kompensasi yang diterima sering merupakan alat satu-satunya bagi kelangsungan hidup secara ekonomis. Kepuasan konsumen (Swastha, 2010) adalah: "Suatu dorongan keinginan individu yang diarahkan pada tujuan untuk memperoleh kepuasan". Dalam hal ini kita perlu mengetahui bahwa suatu keinginan itu harus diciptakan atau didorong sebelum memenuhi motif Sumber yang mendorong terciptanya suatu keinginan dapat berbeda dari diri orang itu sendiri atau berada pada lingkungannya. Kotler (2007: 46) menandaskan bahwa kepuasan konsumen adalah tingkat perasaan seseorang setelah membandingkan kinerja (atau hasil) yang ia rasakan dibandingkan dengan harapannya. Bila kinerja melebihi harapan mereka akan merasa puas dan sebaliknya bila kinerja tidak sesuai harapan maka akan kecewa. Menurut Irawan (2008: 3) kepuasan konsumen adalah hasil dari penilaian dari konsumen bahwa produk atau pelayanan telah memberikan tingkat kenikmatan dimana tingkat pemenuhan ini bisa lebih atau kurang

Berdasarkan definisi di atas dapat ditarik kesimpulan bahwa pada dasarnya pengertian kepuasan konsumen mencakup perbedaan antara harapan dan kinerja atau hasil yang dirasakan. Penilaian kepuasan konsumen mempunyai tiga bentuk yang berbeda yaitu; 1) Positif disconfirmation, di mana kinerja lebih baik dari harapan, 2) Simple confirmation, di mana kinerja sama dengan harapan, dan 3) Negatif disconfirmation, di mana kinerja lebih buruk dari harapan. Pada dasarnya tujuan dari suatu bisnis adalah untuk menciptakan para konsumen yang merasa puas. Setiap orang atau organisasi (perusahaan) harus bekerja dengan konsumen internal dan eksternal untuk memenuhi kebutuhan mereka bekerjasama dengan pemasok internal dan eksternal demi terciptanya kepuasan konsumen. Berdasarkan latar belakang, rumusan masalah, dan tujuan penelitian maka dibuat hipotesis sebagai berikut:

H-1 : Kualitas Pelayanan $\left(\mathrm{X}_{1}\right)$ mempunyai signifikan terhadap Kepuasan awak kapal pada PT. FOC Indonesia (Y), H-2 : Kompensasi $\left(\mathrm{X}_{2}\right)$ mempunyai signifikan terhadap Kepuasan awak kapal pada PT. FOC Indonesia (Y), H-3 : Kualitas Pelayanan $\left(\mathrm{X}_{1}\right)$, dan Kompensasi $\left(\mathrm{X}_{2}\right)$ secara bersama-sama mempunyai hubungan signifikan terhadap Kepuasan awak kapal pada PT. FOC Indonesia (Y). Kerangka Berpikir dari penelitian ini sebagai berikut

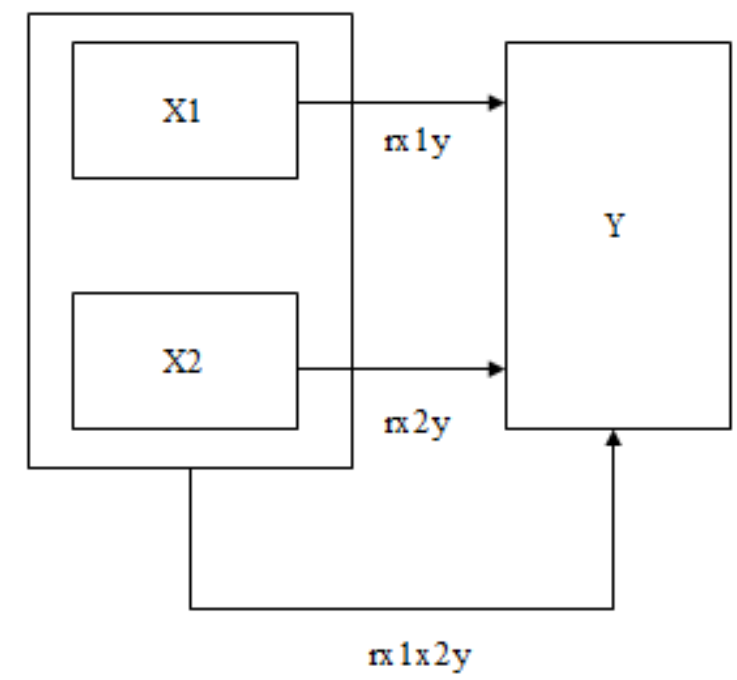

Gambar 1. Model Konstelasi Penelitian

Keterangan:

Variabel bebas $\quad: \quad \mathrm{X} 1 \quad=$ Kualitas pelayanan

Variabel bebas $\quad: \quad \begin{array}{ll}\mathrm{X} 2 & =\text { Kompensasi } \\ \text { Y } & =\text { Kepuasan awak kapal }\end{array}$

Koefisien korelasi : $\quad$ rx1y $=$ Koefisien korelasi X1 dan Y

$\mathrm{Rx} 2 \mathrm{y}=$ Koefisien korelasi X2 dan Y

$\mathrm{rx} 1 \mathrm{x} 2 \mathrm{y}=$ Koefisien korelasi $\mathrm{X} 1$ dan $\mathrm{X} 2$ secara bersama-sama dengan $\mathrm{Y}$ 


\section{METODE}

Metode penelitian yang digunakan dalam penelitian ini metode deskriptif, Hubungan tersebut merupakan hubungan antara dua variabel sebagaimana tujuan metode Assosiatif yaitu untuk mengetahui ada tidaknya hubungan antara variabel bebas dengan variabel terikat (STMT Trisakti, 2007: 3), sedangkan data yang diperoleh dalam penelitian ini adalah data kuantitatif yaitu data berupa angka-angka. Populasi dalam penelitian ini adalah seluruh anak buah PT. FOC Indonesia, sampai dengan pada bulan Januari 2015 yang berjumlah 146 orang awak kapal.

\section{HASIL DAN PEMBAHASAN}

Gambaran tentang karakteristik berdasarkan status responden yang diteliti nampak pada tabel 1 sebagai berikut :

Tabel 1. Status Responden

\begin{tabular}{ccc}
\hline Status & Jumlah (orang ) & Prosentase (\%) \\
\hline Menikah & 42 & $70 \%$ \\
\hline Belum Menikah & 18 & $30 \%$ \\
\hline Jumlah & 60 & $100 \%$ \\
\hline
\end{tabular}

Sumber : Data primer

Berdasarkan tabel 2 di atas dapat diketahui bahwa sebanyak 42 (70\%) responden berstatus menikah dan sebanyak 18 (30\%) responden berstatus belum menikah. Jadi sebagian besar Awak Kapal pada PT. FOC Indonesia Jakarta berstatus menikah. berikut :

Gambaran tentang karakteristik berdasarkan usia responden yang diteliti nampak pada tabel 2 sebagai

Tabel 2. Usia Responden

\begin{tabular}{ccc}
\hline Tingkat Usia & Jumlah (orang) & Prosentase (\%) \\
\hline$<25$ tahun & - & - \\
\hline $25-45$ tahun & 44 & $73,33 \%$ \\
\hline$>45$ tahun & 16 & $26,67 \%$ \\
\hline Jumlah & 60 & \\
\hline
\end{tabular}

Sumber : Data primer diolah, 2014

Berdasarkan tabel 3 di atas dapat diketahui bahwa 44 orang $(73,33 \%)$ responden berusia $25-45$ tahun, sebanyak 16 orang $(26,67 \%)$ berusia lebih dari 45 tahun. Jadi mayoritas Awak Kapal pada PT. FOC Indonesia Jakarta berusia antara 25-34 tahun. Gambaran tentang karakteristik berdasarkan pendidikan responden yang diteliti nampak pada tabel 4.3 sebagai berikut:

Tabel 3 Status Pendidikan

\begin{tabular}{ccc}
\hline Tingkat Pendidikan & Jumlah (orang) & Prosentase (\%) \\
\hline SD & - & - \\
\hline SMP & - & - \\
\hline SMA & 44 & $73,33 \%$ \\
\hline Diploma III & 12 & $20,00 \%$ \\
\hline Diploma IV & 4 & $6,67 \%$ \\
\hline Jumlah & 60 & 100 \\
\hline
\end{tabular}

Sumber : Data primer diolah, 2014

\section{Uji Reliabilitas}

Apabila alpha cornbach lebih besar 0,600, maka dikatakan pertanyaan-pertanyaan reliabel. 
Tabel 4. Uji Reliabilitas Item-Item

\begin{tabular}{lcr}
\hline \multicolumn{1}{c}{ Variabel Penelitian } & Alfa Cornbach & Keterangan \\
\hline Kualitas Pelayanan (X2) & 0,885 & Reliabel \\
\hline Kompensasi (X3) & 0,936 & Reliabel \\
\hline Kepuasan Awak Kapal (Y) & 0,909 & Reliabel \\
\hline
\end{tabular}

Sumber :Data primer diolah

Berdasarkan tabel reliabilitas menunjukkan bahwa keseluruhan item yang digunakan sebagai alat ukur variabel Kualitas Pelayanan (X1), Kompensasi (X2) dan Kepuasan Awak Kapal PT. FOC Indonesia $\operatorname{Jakarta}(Y)$ reliabel. Hal ini di lihat nilai alpha cornbach di atas (>) 0,600.

\section{Uji Normalitas}

Uji normalitas data adalah suatu keharusan untuk mendapatkan kesimpulan yang valid, maka peneliti menggunakan Test Kolmogorov-Smirnov untuk menguji kenormalan data. Dengan kaidah keputusan jika signifikansi lebih besar dari $\alpha=0,05$ (taraf kesalahan 5\%) maka dapat dikatakan data tersebut normal.

Tabel 5 Uji Normalitas

\section{One-Sample Kolmogorov-Smirnov Test}

\begin{tabular}{|ll|r|}
\hline & & $\begin{array}{r}\text { Unstandardiz } \\
\text { ed Residual }\end{array}$ \\
\hline $\mathrm{N}$ & & 60 \\
Normal Parametersa,b & Mean &, 0000000 \\
& Std. Deviation & 5,17355611 \\
Most Extreme & Absolute &, 064 \\
Differences & Positive &, 064 \\
& Negative &,- 057 \\
Kolmogorov-Smirnov Z & &, 496 \\
Asymp. Sig. (2-tailed) &, 966 \\
\hline
\end{tabular}

a. Test distribution is Normal.

b. Calculated from data.

Pada tabel Kolmogorof-Smirnov Test didapatkan nilai signifikansi residualnya sebesar 0,966 yang berarti lebih dari $0,05(\alpha=5 \%)$, maka dapat disimpulkan bahwa model tersebut adalah normal.

\section{Analisis Korelasi}

Korelasi X1 dan X2 dengan Y (ganda), Korelasi ganda, guna mengetahui seberapa erat hubungan antara keseluruhan variabelX1 dan $\mathrm{X}$ 2, dengan variabel terikat $\mathrm{Y}$, dengan rumus sebagai berikut:

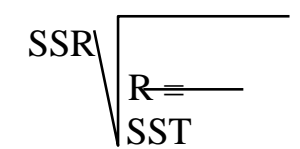

Hasil perhitungan SPSS adalah sebagai berikut:

Tabel 6. Tabel R Square 
Model Summary

\begin{tabular}{|l|r|r|r|r|}
\hline Model & $\mathrm{R}$ & $\mathrm{R}$ Square & $\begin{array}{c}\text { Adjusted } \\
\text { R Square }\end{array}$ & $\begin{array}{c}\text { Std. Error of } \\
\text { the Estimate }\end{array}$ \\
\hline 1 &, $758^{\mathrm{a}}$ &, 574 &, 559 & 5,264 \\
\hline
\end{tabular}

a. Predictors: (Cons tant), Kompensasi (X2), Kualitas Pelayanan (X1)

Dari perhitungan korelasi berganda diperoleh $\mathrm{R}$ sebesar 0,758. Dari hasil tersebut, tampak bahwa hubungan variabel Kualitas Pelayanan $\left(\mathrm{X}_{1}\right)$, dan Kompensasi (X2), secara bersama-sama dengan Kepuasan Awak Kapal (Y) adalah kuat dan searah (positif).

\section{Uji Hipotesis Korelasi X1, X2 dengan Y (ganda)}

Bertujuan untuk mengetahui apakah secara berganda ada atau tidak hubungan antara kualitas pelayanan dan kompensasi dengan kepuasan awak kapal dengan hipotesis:

H3 : ada hubungan kualitas pelayanan dan kompensasi secara bersama-sama dengan kepuasan awak kapal. Menggunakan tabel F

$\mathrm{F}$ tabel

$$
=\mathrm{F}(1-\alpha)\{\mathrm{dk}=\mathrm{k}),(\mathrm{dk}=\mathrm{n}-\mathrm{k}-1)\}
$$

$=\mathrm{F}(1-\alpha)\{\mathrm{dk}=2),(\mathrm{dk}=60-2-1)\}$

$=\mathrm{F}(1-0,05)(2,57)$

Cara mencari $\mathrm{F}$ tabel $=2$, sebagai angka pembilang

$=57$, sebagai angka penyebut

F tabel

1) Menghitung nilai statistic Uji $F$

F hitung $=\frac{R^{2} / k}{\left(1-R^{2}\right) /(n-k-1)}=\frac{0,473 / 2}{0,473 / 57}=38,401$

2) Membandingkan nilai statistic uji dengan daerah tabel

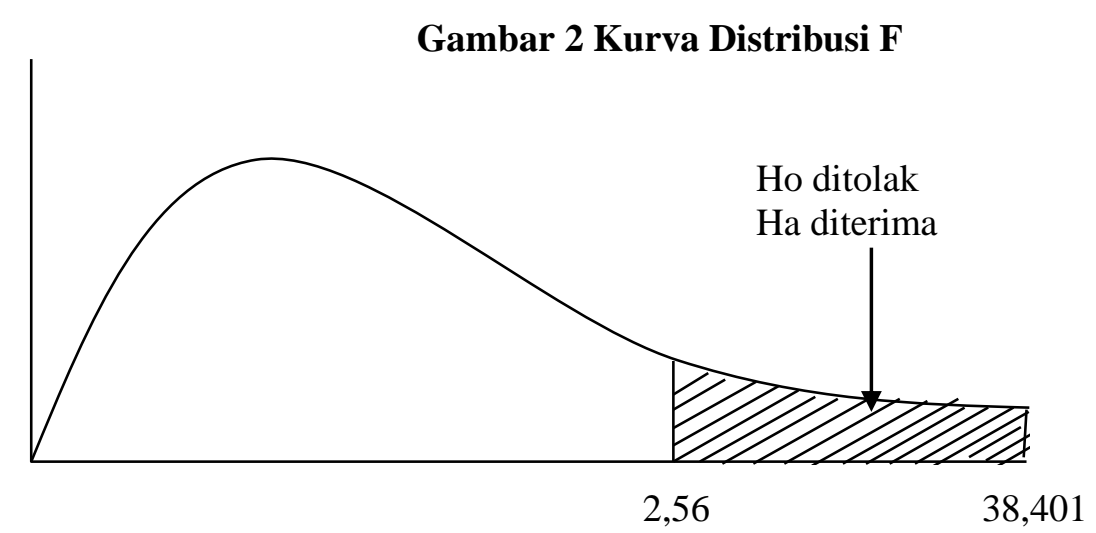

\section{3) Menarik Kesimpulan}

Berdasarkan hal tersebut bahwa $\mathrm{F}$ hitung $>\mathrm{F}$ tabel atau 38,401> 2,56 artinya ada hubungan yang signifikan kualitas pelayanan dan kompensasi secara bersama-sama dengan kepuasan awak kapal, degan demikian hipotesis penelitian H4 diterima. Koefisien Determinasi X1, X2 dengan Y, Berikut hasil koefisien determinasi dari R square:

\section{Tabel 7. R Square}


Model Summary

\begin{tabular}{|l|r|r|r|r|}
\hline Model & $\mathrm{R}$ & $\mathrm{R}$ Square & $\begin{array}{c}\text { Adjusted } \\
\text { R Square }\end{array}$ & $\begin{array}{r}\text { Std. Error of } \\
\text { the Estimate }\end{array}$ \\
\hline 1 &, $758^{\mathrm{a}}$ &, 574 &, 559 & 5,264 \\
\hline
\end{tabular}

a. Predictors: (Constant), Kompensasi (X2), Kualitas

Pelayanan (X1)

Dengan melihat hasil perhitungan di atas dimana $\mathrm{R}$ square sebesar 0,574 atau $57,4 \%$. Hal ini menunjukkan besarnya kontribusi kualitas pelayanan dan kompensasi secara bersama-sama dengan kepuasan awak kapalsebesar 57,4\%, sedangkan sisanya 42,6\% merupakan pengaruh faktor lain di luar model penelitian.

\section{KESIMPLAN DAN SARAN}

Hasil penelitian membuktikan kualitas pelayanan jasa pengawakan dalam menunjang pelayanan Awak Kapal PT. FOC Indonesia Jakarta dapat dikatakan berkualitas. Dari kelima dimensi pelayanan yang digunakan untuk mengukur kualitas pelayanan yaitu Keandalan (reliability), Daya Tanggap (responsiveness), Keyakinan (assurance), Perhatian (emphaty), serta dimensi Berwujud (tangibles) mendapat respon positif dari pengguna jasa. PT. FOC Indonesia Jakarta diharapkan bisa meningkatkan kualitas pelayanannya kepada pengguna jasa, terutama dalam hal kecepatan dan ketepatan dalam melayani Awak Kapal, sehingga Awak Kapal tidak merasa dirugikan dan dapat merasakan kepuasan dari pelayanan yang diberikan. Penanganan keluhan Awak Kapal juga harus dilakukan dengan serius agar Awak Kapal tidak kecewa dengan pelayannan yang diberikan sehingga Awak Kapal akan selalu berulang-ulang menggunankan pelayanan jasa pengawakan pada PT. FOC Indonesia Jakarta.

Variabel kompensasi mempunyai pengaruh signifikan terhadap peningkatan kepuasan awak Kapal PT. FOC Indonesia Jakarta. Kompensasi merupakan variabel yang berpengaruh dominan terhadap kepuasan awak Kapal PT. FOC Indonesia Jakarta. Kompensasi berupa gaji, pemberian seniority, penggantian biaya keberangkatan dan promosi jabatan berpengaruh dominan terhadap kepuasan awak Kapal PT. FOC Indonesia Jakarta. Hal ini memberikan makna bahwa kompensasi berupa gaji merupakan daya tarik yang menyebabkan seseorang melakukan sesuatu karena adanya imbalan yang akan memuaskan kebutuhannya. Pertimbangan ini berkaitan dengan tingkat kepuasan yang akan diperoleh, jika usaha ditingkatkan menjadi suatu pelaksanaan, jika pelaksanaan itu berhasil dan jika imbalan yang dijanjikan diterima. Besarnya gaji yang diterima Awak kapal tersebut harus sesuai dengan dua kriteria, yaitu seberapa jauh kebutuhan itu akan terpenuhi dan apakah imbalan tersebut sesuai dengan usaha yang dilakukan dalam menjalankan kegiatan tersebut. Jika hal ini sudah dirasakan sesuai, maka proses motivasi akan bergerak pada tingkat berikutnya yaitu kemungkinan bahwa individu tersebut melakukan kegiatan itu, sehingga dia memperoleh imbalan yang dijanjikan. Atau dengan kata lain, setelah dia mempertimbangkan bahwa insentif yang akan diterima sesuai atau dapat memuaskan motif yang ada, maka individu tersebut juga akan mempertimbangkan kemungkinan dia berhasil melaksanakan tugasnya atau kegiatan tersebut.

Hasil-hasil penelitian membuktikan kualitas pelayanan dan kompensasi secara simultan mempunyai pengaruh signifikan terhadap Kepuasan Awak Kapal PT. FOC Indonesia Jakarta. Hal ini memiliki makna bahwa keberhasilan suatu organisasi dipengaruhi oleh Kepuasan Awak Kapal. Kepuasan Awak Kapal mencerminkan perasaan seseorang terhadap pekerjaannya. Hal ini nampak dalam sikap positif Awak Kapal terhadap pekerjaan dan segala sesuatu yang dihadapi dilingkungan kerjanya. Kualitas pelayanan dan kompensasi menjadi hal penting karena dapat mempengaruhi kepuasan Awak Kapal.

\section{Daftar Pustaka}

Adenan Suhalis. 1995 . Metode Penelitian Sosial. Jakarta : Mawar Gempita

Aryani, D dan Rosinta, F. 2010. Pengaruh kualitas Layanan Terhadap Kepuasan Pelanggan Dalam Membentuk Loyalitas Pelanggan.Jurnal Ilmu Administrasi dan Organisasi.Vol.17.No.2. 
Arikunto, Suharsimi. 2007, Prosedur Penelitian Suatu Pendekatan Praktek. Edisi Kedua. Rineka Cipta. Jakarta.

Assauri sofyan 2007, Manajemen Pemasaran dan Pemasaran Jasa, penerbit CV. Alfa Beta, Bandung.

Bahar dkk.2009, pengaruh kualitas pelayanan terhadap kepuasan dan loyalitas pengguna angkutan umum informal. Simposium XII FSTPT, Universitas Kristen Petra Surabaya.

Eka Idham Iip K Lewa, Subowo, 2005. Pengaruh Kepemimpinan, Lingkungan Kerja Fisik Dan Kompensasi Terhadap Kinerja Karyawan di PT.Pertamina (Persero) Daerah Operasi HuluJawa Bagian Barat, Cirebon.ISSN : $1410-9018$.

Flippo, Edwin B. 2005. Manajemen Sumber Daya Manusia, dalam Hasibuan 2005, Cetakan Ketujuh, Sinar Grafika Offset, Jakarta.

Gitosudarmo, 2005, Perilaku Keorganisasian, Edisi Pertama, Cetakan Pertama, BPFE, Yogyakarta.

Goetsch, Davis. 2007.Consumer Behavior Buying, Having and Being. (7thed.). New Jersey: Person Prentice Hall. Terjemahan Tjiptono, Fandi cetakan Peertama, Andy Yogyakarta.

Hariandja, 2008, Manajemen Sumber Daya Manusia (Kebijaksanaan Kerja Karyawan), BPFE, Yogyakarta.

Hasibuan,2005Manajemen Sumberdaya Manusia Perusahaan. PT. Remaja Rosdakarya, Bandung.

Handoko ,2007, Manajemen Personalia dan Sumber Daya Manusia, BPFE, Yogyakarta.

Irawan, Handi, 2008, 10 Prinsip Kepuasan Pelanggan, Cetakan ke-10, PT. Elex Media Komputindo, Jakarta.

Kotler, Philip., 2007, Manajemen Pemasaran Edisi Milenium Jilid1dan2, Terjemahan oleh Hendra Teguh dan Ronny A.Rusli, PT Prenhalindo, Jakarta.

Lupiyoadi, R dan Hamdani, 2006, Manajemen Pemasaran Jasa Teori dan Praktek, Edisi Pertama., Penerbit Salemba Empat, Jakarta.

Michael, L and Harold, W.P 2008Money is Everything.Annual Report Human Resources Management.

Mondy, R.W and Noe, R M 2008, Human Resources Management. Allyn and Bacon Inc. USA.

Manulang, 2005, "Manajemen Personalia", Ghalia Indonesia, Jakarta.

Moekijat 2006, Perilaku Konsumen dan Komunikasi Pemasaran, PT. Remaja Rosdakarya, Bandung.

Munawaroh 2005, Analisis Pengaruh Kualitas Layanan Terhadap KepuasanPelanggan Rumah Makan KETTY RESTO. Jurnal Ekonomi dan Informasi Akuntansi. Vol. 1. No. 3.

Nasution, M.N., 2005. Manajemen Mutu Terpadu (Total Quality Management), Edisi Kedua. Ghalia Indonesia, Bogor.

Nawawi, Handari, 2007, Manajemen Personalia, Cetakan Ketiga, Penerbit Gajah Mada Universitas Press, Yogyakarta.

Parasuraman, et al,2007, Manajemen Pemasaran (Dasar, Konsep dan Strategi),Cetakan Keempat, CV. Rajawali, Jakarta.

Singaribuan, Masri,2007, Metodologi Penelitian Survei, LP3ES. Jakarta.

Soetjipto, 2007, Service Quality : Alternatif Pendekatan dan Berbagai Persoalan di Indonesia, Usahawan, Tahun XXVI.

Swasta, Basu Dharmmesta, 2010, Manajemen Pemasaran :Analisis Perilaku Konsumen, Edisi Pertama, Cetakan Ketiga, BPFE Yogyakarta.

Sugiyono, 2007, Metodologi Penelitian Administrasi.Cetakan Kedelapan. Alfabeta. Bandung.

Thoha, Miftah, 2005 Perilaku Konsep Dasar dan Aplikasinya, Cetakan Kesepuluh, Raja Grafindo Persada, Jakarta.

Tjiptono, Fandi, 2007, Strategi Pemasaran, Edisi Kedua, cetakan Peertama, Andy Yogyakarta.

Zeithaml, et al. 2007. Service Marketing. Singapore: Mc Graw-Hill Companies Inc.: 3-287.

Widayat dan Amirullah, 2008, Metode Penelitian Pemasaran, UMM Press, Malang.

Werther and Davis, 2007, The Influence of Job Satisfaction and Organizational Commitment and Executive Withdrawl and Performance. Working Paper 00-16, CAHRS, Cornell School of Industrial and Labour Relation .

Wendha et al, 2013, Pengaruh Kualitas Layanan Terhadap Kepuasan Dan Loyalitas Pelanggan Garuda Indonesia Di Denpasar, Jurnal Manajemen, Strategi Bisnis, dan Kewirausahaan Vol. 7, No. 1, Februari 2013. 